Short communication

\title{
Optimization of pulsed field gel electrophoresis (PFGE) conditions for thermophilic bacilli
}

\author{
Elif Yavuz ${ }^{1}$, Hatice Gunes ${ }^{2}$, Sebnem Harsa ${ }^{1}$, Cisem Bulut ${ }^{2}$ and A. Fazil Yenidunya ${ }^{2, *}$ \\ ${ }^{1}$ Biotechnology and Bioengineering Programme, Izmir Institute of Technology, 35430 Gulbahce, Izmir, Turkey \\ ${ }^{2}$ Department of Biology, Science Faculty, Izmir Institute of Technology, 35430 Gulbahce, Izmir, Turkey \\ *Author for correspondence: Tel.: +90-232-750-7545, Fax: +90-232-750-7509, E-mail: afazilyenidunya@iyte.edu.tr
}

Received 5 November 2003; accepted 13 May 2004

Keywords: DNA degradation, genotyping, pulsed field gel electrophoresis, thermophilic Bacillus

\begin{abstract}
Summary
Although thermophilic members of the genus Bacillus are known to tolerate extreme environmental conditions, they appeared to be readily damaged upon mechanical manipulations. This fact was evidenced in genotyping of some strains of thermophilic Bacillus by pulsed field gel electrophoresis (PFGE). Consequently, a new procedure for the preparation of agarose plugs was developed. The procedure produced interpretable genomic DNA restriction profiles.
\end{abstract}

\section{Introduction}

Pulsed field gel electrophoresis (PFGE) has been widely used for the molecular typing of bacteria because it is a very powerful technique in differentiating microorganisms below the species level (Tanskanen et al. 1990; Tenover et al. 1995; Olive \& Bean 1999; Vela et al. 2000; Moschetti et al. 2001; Rivera et al. 2003), and for the analysis of microbial genomes (Carlson et al. 1993). It has however been experienced that not all bacteria, such as thermophilic bacilli, could be embedded into agarose using ordinary plug moulds and plug-making procedures, without causing physical damage to the cells. In this report, a new procedure for the embedding of bacteria in agarose plugs is described that avoids the problem. Bacterial cultures were prepared on solid media and were then suspended in cell suspension buffer by manual stirring. The plugs were also formed by mixing the agarose and cell suspension with a spatula on the opened and one side of the reusable plug moulds. Therefore the procedure avoided all centrifugation steps and pipetting of the cells.

\section{Materials and methods}

Bacillus thermoglucosidasius (CECT 4038T), Bacillus stearothermophilus (CECT43), and Bacillus kaustophilus (CECT 4264) were obtained from Colleccion Espanola de Cultivos Tipo (CECT), Universidad de Valencia, Burjasof, Spain. Bacillus clausii (NRRL B-23342), Bacillus clarkii (NRRL B-23344), and Bacillus halmap- alus (NRRL B-23347) were obtained from the US Agricultural Research Service Culture Collection (ARS/ NRRL; Peoria, IL, USA). Strains 3, 4, 9, 20 and 92 were the local isolates from Balcova, Izmir. All the strains were cultured at $55^{\circ} \mathrm{C}$ and were then kept at $-80{ }^{\circ} \mathrm{C}$ in $20 \%$ glycerol stocks.

A set of experiments was performed for the genotyping of thermophilic Bacillus by following the PFGE procedures reported by Birren \& Lai (1993), Bouton et al. (1998), and Bio-Rad's Manufacturer's manual (Catalog Nr. 170-3612 through 170-3729). In these protocols, bacterial cells are first pelleted by centrifugation and are then mixed with agarose by pipetting to form agarose plugs. However, after the observation of non-specific degradation of genomic DNA, the plug preparation step was modified and used as described below.

Bacterial cultures were streaked from frozen glycerol stocks onto nutrient agar plates and were then incubated overnight at $55^{\circ} \mathrm{C}$. The reusable 15 -welled plug-mould holder (Bio-Rad) was unscrewed and agarose plugs were prepared using only one side of the mould holder. The cells were embedded in agarose as follows. Onto the open moulds, $100 \mu \mathrm{l}$ of cell suspension buffer $(10 \mathrm{mM}$ Tris- $\mathrm{HCl}, \mathrm{pH}$ 7.2; $20 \mathrm{mM} \mathrm{NaCl} ; 50$ mM EDTA, pH 8) were pipetted. The colonies were then scraped with a platinum loop into this cell suspension buffer. Using the edge of a steel spatula, the cells were then suspended by gentle mixing. After the cells were homogenously suspended, $100 \mu \mathrm{l}$ of $1.5 \%$ low melting temperature agarose (Applichem) solution (in sterile water, kept at $50{ }^{\circ} \mathrm{C}$ ) were added dropwise onto the cell suspension. 
Agarose and cells were mixed by using the edge of the spatula and by gentle stirring. The plugs were then allowed to solidify. The cells were lysed by transferring the plugs into $1.5 \mathrm{ml}$ eppendorf tubes containing $500 \mu \mathrm{l}$ lysozyme solution $(10 \mathrm{mM}$ Tris- $\mathrm{HCl}, \mathrm{pH} 7.2 ; 50 \mathrm{mM}$ $\mathrm{NaCl} ; 0.2 \%$ sodium deoxycholate; $0.5 \%$ sodium $N$-lauroylsarcosinate; and $1 \mathrm{mg}$ lysozyme $/ \mathrm{ml}$ ), and were then incubated for $1 \mathrm{~h}$ at $37^{\circ} \mathrm{C}$ without agitation. The plugs were transferred into $50 \mathrm{ml}$ Falcon tubes containing $2.5 \mathrm{ml}$ of $1 \times$ wash buffer $(20 \mathrm{mM}$ Tris- $\mathrm{HCl}, \mathrm{pH} 8$; $50 \mathrm{mM}$ EDTA, $\mathrm{pH} 8$ ) and rinsed by gentle agitation for $45 \mathrm{~min}$ at room temperature on an orbital shaker. The plugs were then transferred into $1.5 \mathrm{ml}$ eppendorf tubes containing $500 \mu \mathrm{l}$ proteinase $\mathrm{K}$ buffer $(100 \mathrm{mM}$ EDTA, pH 8; 0.2\% sodium deoxycholate; $1 \%$ sodium $\mathrm{N}$-lauroylsarcosinate; $1 \mathrm{mg}$ proteinase $\mathrm{K} / \mathrm{ml}$ ), and were incubated for $18 \mathrm{~h}$ at $50{ }^{\circ} \mathrm{C}$ without agitation. Prior to restriction enzyme digestion, the plugs were washed four times in $2.5 \mathrm{ml}$ wash buffer: first and second washes were in $1 \times$ wash buffer plus $1 \mathrm{mM} \mathrm{NaCl}$. Third wash was in $1 \times$ wash buffer plus $1 \mathrm{mM}$ PMSF (phenylmethylsulphonyl fluoride). Fourth wash was in $1 \times$ wash buffer.

After equilibrating the plugs in $1 \times S m a$ I restriction enzyme buffer (Fermentas) for $1 \mathrm{~h}$ at room temperature with gentle agitation, genomic DNA was digested with 30 units of SmaI in $300 \mu \mathrm{l}$ reaction volume overnight at $30{ }^{\circ} \mathrm{C}$. The plugs were equilibrated in $1 \mathrm{ml}$ of $1 \times \mathrm{TBE}$ (90 $\mathrm{mM}$ Tris-borate; $2 \mathrm{mM}$ EDTA, $\mathrm{pH} 8$ ), and were then cut to the size of the combs and loaded into $1 \%$ agarose gel (PFGE grade agarose, Bio-Rad). The agarose wells were covered with \% 1 low melting agarose (in $1 \times \mathrm{TBE}$ ). The chamber was filled with 21 of $1 \times$ TBE. Electrophoresis was performed in a $\mathrm{CHEF}$ DRII system (Bio-Rad) with 1-8 pulse times, for $26 \mathrm{~h}$ at $4 \mathrm{~V} / \mathrm{cm}$ at $14{ }^{\circ} \mathrm{C}$. After the electrophoresis, the gel was stained in $3 \mu \mathrm{g} / \mathrm{ml}$ ethidium bromide solution for $25 \mathrm{~min}$. Following $1 \mathrm{~h}$ destaining, the image of the gel was analysed in a gel documentation system (Bio1D++ software, Vilber-Lourmat).

RFLP patterns were stored into and refined by Adobe Photoshop 7.0 and were then analysed by using BIO$1 \mathrm{D}++$ software (Vilber-Lourmat, France). The similarity between strains was determined automatically by specifying the formula of Nei and Li (Vilber-Lourmat). Strain clustering was performed by the un-weighted pair group method with arithmetic averages, UPGMA (BIO-1D++, Vilber-Lourmat).

\section{Results and discussion}

Prior to the new plug preparation technique, a number of other methods were repeatedly tried for the embedding of thermophilic bacilli into agarose plugs (Birren \& Lai 1993; Bouton et al. 1998; CHEF DR II Manufacturer's manual, Bio-Rad). At the beginning of the study, after observing un-interpretable DNA profiles, sequential modifications were made on the method by changing

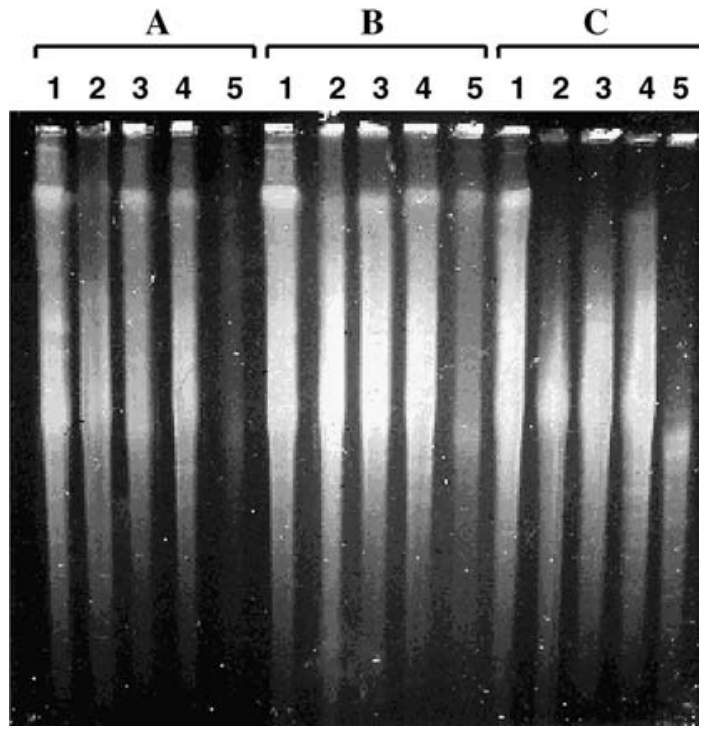

Figure 1. (A) Incubation of the agarose plugs overnight at $4{ }^{\circ} \mathrm{C}$. (B) Incubation of the agarose plugs in $S m a \mathrm{I}$ buffer overnight at $30^{\circ} \mathrm{C}$. (C) SmaI digested plugs. All the groups include the following Bacillus cells in the same order: Lane 1, Bacillus thermoglucosidasius (CECT 4038T); lane 2, Bacillus kaustophilus (CECT 4264); lane 3, Bacillus stearothermophilus (CECT 43); lane 4, isolate 4; and lane 5, isolate 9.

one parameter at a time to find out where the DNA was degraded. These included elimination of centrifugation steps, decreasing the amount of lysozyme, decreasing the EDTA concentration in the cell suspension buffer, decreasing the amount of restriction enzyme and the incubation time, eliminating proteinase $\mathrm{K}$ digestion, and decreasing the number of washing steps (data not shown). It was finally found out that DNA was degraded during the embedding of bacteria into the agarose plugs.

Five different Bacillus members, Bacillus thermoglucosidasius (CECT 4038T), Bacillus kaustophilus (CECT 4264), Bacillus stearothermophilus (CECT 43), 4 and 9 (isolated strains) were each embedded into three sets of agarose plugs. One set of the plugs was incubated in cell suspension buffer overnight at $4{ }^{\circ} \mathrm{C}$ and was then analysed by PFGE (Figure 1A). The second group was further treated with lysozyme and proteinase K. After the washing steps, they were kept overnight at $4{ }^{\circ} \mathrm{C}$ in $1 \times$ SmaI restriction enzyme buffer instead of restriction enzyme digestion (Figure 1B). The third set of agarose plugs were digested with $S m a$ I restriction endonuclease after the lysozyme and proteinase $\mathrm{K}$ treatments, and washing steps (Figure 1C). Since non-specific degradation of DNA was observed in all lanes, this experiment indicated that genomic DNA shearing started at the plug preparation procedure and that physical manipulations, even micropipetting for example, could introduce some physical damage to the cells and initiate subsequent shearing of the chromosomal DNA.

The problem was overcome by using the new plug preparation method (Figure 2): in the gel three type strains, Bacillus thermoglucosidasius (CECT 4038T), 


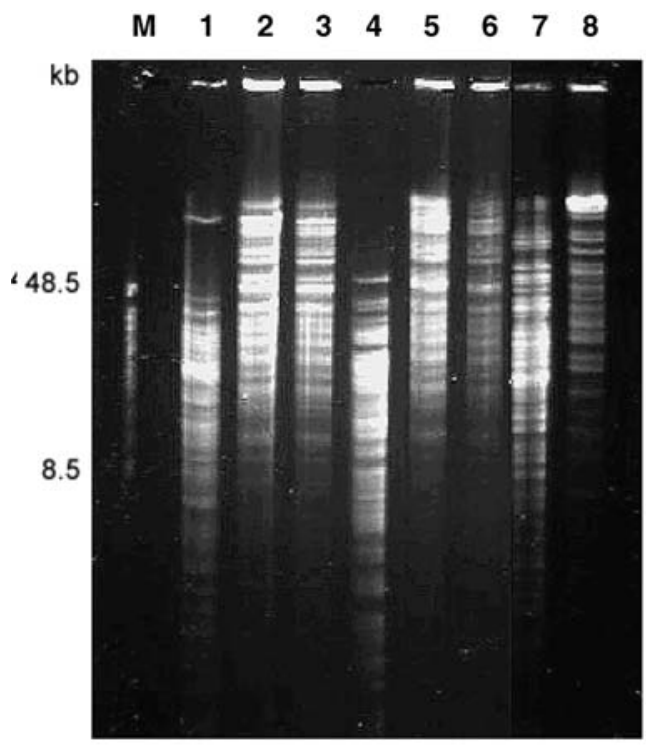

A

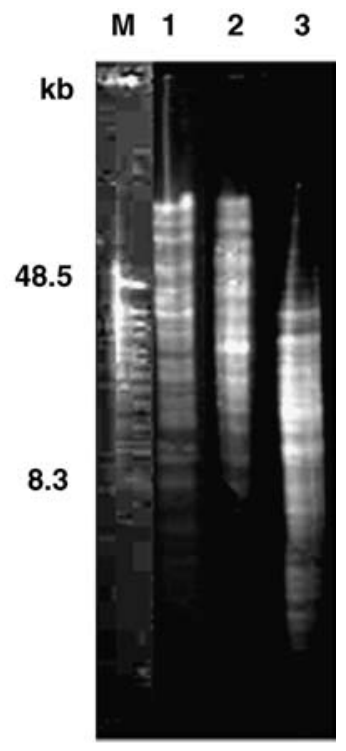

B

Figure 2. (A) SmaI digested samples of thermophilic Bacillus: Lane 1, Bacillus thermoglucosidasius (CECT 4038T); lane 2, isolate 4; lane 3, isolate 9; lane 4, isolate 20; lane 5, isolate 3; lane 6, isolate 92; lane 7, Bacillus kaustophilus (CECT 4264); and lane 8, Bacillus stearothermophilus (CECT 43). (B) SmaI digested samples of mesophilic Bacillus Lane 1, Bacillus clarkii (NRRL B-23344); lane 2, Bacillus halmapalus (NRRL B-23347); lane 3, Bacillus clausii (NRRL B-23342). (M) 8-48 kb DNA Ladder (Bio-Rad).

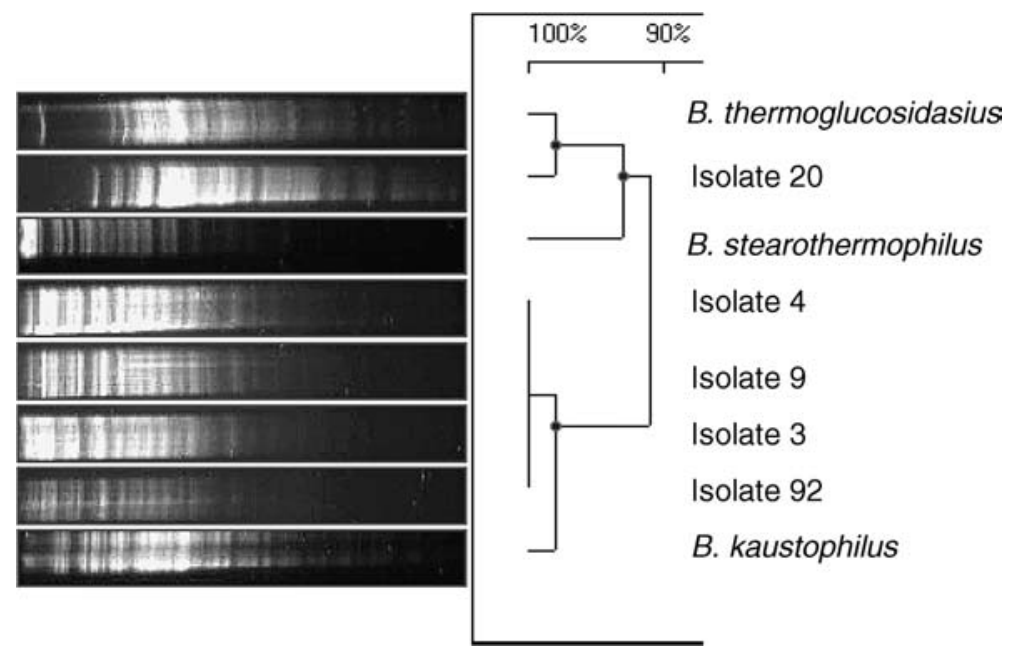

Figure 3. Cluster analysis: Restriction enzyme profiles of three reference strains and five local isolates were compared. The restriction fragmentation patterns (left) and respective names of the strains (right) were shown.

Bacillus kaustophilus (CECT 4264), and, lanes 1, 7, and 8, respectively, could be readily differentiated. It was also obvious that four of our local isolates (lanes 2, 3, 5, and 6) had identical fragmentation patterns. These findings were also evident in the cluster analysis (Figure 3 ). Two main clusters were apparent: One of the clusters contained two of the reference strains, B. thermoglucosidasius and B. stearothermophilus, together with isolate 20. Four of the local isolates (4, 9, 3, and 92), on the other hand, showed $100 \%$ similarity within themselves, and were clustered with B. kaustophilus.

To determine whether the new plug-making procedure could work with other bacteria, chromosomal DNA patterns of three reference strains of mesophilic Bacillus,
Bacillus clausii (NRRL B-23342), Bacillus clarkii (NRRL B-23344), and Bacillus halmapalus (NRRL B23347) were also analysed by PFGE using the new procedure (Figure 2B). This procedure will be further improved by PFGE-genotyping of our local thermophilic Bacillus isolates.

\section{Acknowledgements}

This work was partially supported by grants from IYTE (2001FEN20; 2002IYTE43). The Authors would like to thank Res. Assist. Mert Sudagidan for his assistance in the computational work. 


\section{References}

Birren, B. \& Lai, E. 1993 Pulsed Field Gel Electrophoresis a Practical Approach. USA: Academic Press Inc., ISBN 0-12-101290-5.

Bouton, Y., Guyot, P. \& Grappin, R. 1998 Preliminary characterization of microflora of Comte cheese. Journal of Applied Microbiology 85, 123-131.

Chef-DR II pulsed field electrophoresis systems, instruction manual and applications guide. Catalog numbers 170-3612 through 1703729, BioRad.

Carlson, C.R. \& Kolsto, A.B. 1993 A complete physical map of a Bacillus thuringiensis chromosome. Journal of Bacteriology 175, 1053-1060.

Moschetti, G., Blaiotta, G., Villani, F. \& Coppolo, S. 2001 Nisin producing organisms during traditional 'Fior di latte' cheese making monitored by multiplex PCR and PFGE analysis. International Journal of Food Microbiology 63, 109-116.

Olive, D.M. \& Bean, P. 1999 Principles and application methods for DNA-based typing of microbial organisms. Journal of Clinical Microbiology 37, 1661-1669.
Rivera, A.M.G. \& Priest, F.G. 2003 Pulsed field gel electrophoresis of chromosomal DNA reveals a clonal population structure to Bacillus thuringiensis that relates in general to crystal protein gene content. FEMS Microbiology Letters 223, 61-66.

Tanskanen, E.I., Tulloch, D.L., Hillier, A.J. \& Davidson, B. 1990 Pulsed field gel electrophoresis of Sma I digests of Lactococcal genomic DNA, a novel method of strain identification. Applied and Environmental Microbiology 56, 3105-3111.

Tenover, F.C., Arbeit, R.D., Goering, R.V., Mickelsen, P.A., Murray, B.E., Persing, D.H. \& Swaminathan, B. 1995 Interpreting chromosomal DNA restriction patterns produced by pulsed-field gel electrophoresis: criteria for bacterial strain typing. Journal of Clinical Microbiology 33, 2233-2239.

Vela, A.I., Vazquez, J., Gibello, A., Blanco, M.M., Moreno, M.A., Liebana, P., Albendea, C., Alcala, B., Mendez, A., Dominguez, L. \& Fernandez-Garayzabal, J.F. 2000 Phenotypic and genetic characterization of Lactococcus garvieae isolated in Spain from Lactococcosis outbreaks and comparison with isolates of other countries and sources. Journal of Clinical Microbiology 38, 37913795 . 